\title{
QUALIDADE DE ENSINO NA MODALIDADE EJA SOB A ÓTICA DOS DOCENTES
}

Debora Cristina Jeffrey

debora.jeffrey@gmail.com

Sandra Fernandes Leite

sfleite@unicamp.br

Universidade Estadual de Campinas

RESUMO: Este artigo apresenta a percepção dos docentes sobre a qualidade de ensino na modalidade EJA, considerando suas condições cotidianas de trabalho. Apresenta os documentos legais e indicativos de qualidade na EJA da Rede Estadual de São Paulo e do Município de Campinas. A análise aborda a qualidade na educação de jovens e adultos baseada em sete dimensões: insumos financeiros e de infraestrutura; gestão pedagógica; prática pedagógica e processo de ensino e aprendizagem; avaliação; formação continuada; relações no espaço escolar e relações no entorno, sob a ótica dos docentes e fazendo um recorte em Campinas/SP, baseou-se na pesquisa "Diagnóstico da qualidade de ensino na Educação de Jovens e Adultos", financiada pelo Observatório da Educação/CAPES. Esta pesquisa realizou o levantamento bibliográfico referente à qualidade de ensino, a formação dos professores, às políticas públicas de EJA no Brasil e às orientações oficiais de âmbito federal, estadual e municipal sobre a EJA.

PALAVRAS-CHAVE: Qualidade de Ensino. Formação de Professores. Indicador de Qualidade. Educação de Jovens e Adultos.

\section{TEACHING QUALITY IN YOUTH AND ADULT EDUCATION (EJA) MODALITY FROM THE PERSPECTIVE OF TEACHERS}

ABSTRACT: This article presents the perception of teachers on teaching quality in Youth and Adult Education (EJA) modality considering their daily working conditions. The paper presents the legal documents and quality indicators in EJA modality in the State of São Paulo and Campinas. The analysis focuses on the quality of education for Youth and Adult people in financial inputs and infrastructure; educational management; pedagogical practice and teaching and learning; evaluation; continuing education; relationships within the school and relationships in the environment. The analysis of quality from the perspective of teachers and taking Campinas/SP as study case was based on the research "Diagnosis of teaching quality in Youth and Adult Education", funded by the Observatório da Educação/CAPES. This research conducted the literature related to quality education, to adult and youth education (EJA) public policy in Brazil and the official guidelines of federal, state and municipal levels on the EJA.

KEYWORDS: Teacher Training. Teaching quality. Quality Indicator. Youth and Adult Education. 


\section{Introdução}

A formação inicial e continuada de professores para atuação na modalidade Educação de Jovens e Adultos (EJA), na primeira década dos anos 2000, representou um desafio pedagógico e acadêmico envolvendo o campo, mas também a constituição de inúmeras possibilidades, pelo fato desta apresentar três funções que se complementam e se contradizem, concomitantemente: a função reparadora, a função equalizadora e a função permanente (BRASIL, 2000). Essas funções, indicadas no Parecer CNE/CEB n. 11/2000, propõem que a modalidade EJA atenda aos seguintes propósitos: a) garantir o direito negado à escolarização (função reparadora); b) garantir a inserção em novos espaços, a partir da formação (função equalizadora); c) capacitar para o mundo do trabalho e experiências do mundo social, cultural e econômico (função permanente/qualificadora). Tais funções podem ser efetivadas em espaços escolares e não escolares, levando a modalidade EJA a estabelecer uma inter-relação com outros campos, tais como a Educação Profissional, Educação Popular, Educação do Campo, Educação nas Prisões, Educação Quilombola, Educação Indígena.

Diante deste fato, a formação inicial e continuada de professores deve, portanto, dialogar com os demais campos, bem como favorecer a formação de um profissional capaz de compreender as especificidades dos sujeitos envolvidos no processo educativo (jovens e adultos) e atender às três funções propostas à modalidade EJA (reparadora, equalizadora e permanente). Nesse sentido, a formação de professores para a atuação na modalidade educação de jovens e adultos vem sendo considerada um grande desafio às instituições voltadas para a formação inicial e continuada, dada a especificidade que envolve o processo de ensino e aprendizagem, bem como a heterogeneidade da população atendida.

Este artigo apresenta a percepção dos docentes sobre a qualidade de ensino na modalidade EJA, considerando suas condições cotidianas de trabalho. Parte do conceito de qualidade na educação e sua aplicabilidade na modalidade EJA. Faz um recorte no município de Campinas/SP e apresenta as principais correntes que têm influenciado as proposições normativas, políticas e pedagógicas que orientam a modalidade, de modo a apontar os desafios e possibilidades de efetividade de propostas de formação e como tais aspectos podem contribuir com a análise dos indicadores de qualidade de ensino. 
A análise dos indicadores de qualidade de ensino, sob a ótica dos docentes do município de Campinas/SP, foi realizada com base nos resultados obtidos com o desenvolvimento da pesquisa em rede, financiada pelo Observatório da Educação/Capes: "Diagnóstico da qualidade de ensino na Educação de Jovens e Adultos (EJA): um estudo de caso", realizado entre pesquisadores das Faculdades de Educação da Universidade Estadual de Campinas (Unicamp), Universidade Estadual do Rio de Janeiro (UERJ) e Universidade Federal de Juiz de Fora (UFJF). Esta pesquisa em rede consistiu no levantamento bibliográfico referente à temática, qualidade de ensino e às políticas públicas para a modalidade, no Brasil. Também foi realizado o levantamento documental de orientações oficiais de âmbito federal, estadual e municipal. Com relação aos indicadores de qualidade apontados pelos docentes de Campinas/SP, estes foram evidenciados após a aplicação de questionários entre esses profissionais (JEFFREY et al., 2014).

\section{Qualidade na educação}

A qualidade da educação é apresentada com diversas definições e interpretações. O termo pode ser entendido com vários significados, pois se relaciona e se ajusta conforme a relevância política, social, cultural ou econômica que possui em um determinado contexto educacional. Brandão (1992) explica esse processo ao compreender que não há um único tipo de educação, mas várias. Elas podem atender diferentes propósitos em cada sociedade, comunidade ou grupo.

Fonseca (2009) considera que a qualidade da educação pode ser definida em diferentes perspectivas:

A responsabilidade do Estado na garantia do direito individual, por meio da oferta, acesso e permanência de todos no sistema de ensino;

As políticas governamentais no estabelecimento de iniciativas que visem a regulação do sistema (avaliação externa), financiamento público, inovação tecnológica, formação do quadro administrativo e de docentes;

A dinâmica das instituições educativas no estabelecimento da gestão institucional, autoavaliação e currículo (FONSECA, 2009, p.25).

O mesmo autor aponta aspectos que podem ser analisados através do caráter atribuído à qualidade da educação pelo Estado e instituições educativas. Demo (2002) denomina este caráter como instrumental (atividades meio) ou político (atividades fins). 
O caráter instrumental refere-se às condições materiais, estruturais e de pessoal oferecidas ao sistema educacional, servindo de base para as reformas educacionais. $\mathrm{O}$ caráter político visa combater a injustiça e as desigualdades por meio de uma perspectiva democrática, com objetivos de garantir a qualidade de vida.

O caráter instrumental e o caráter político coexistem e podem nortear as ações, iniciativas e políticas educacionais estabelecidas pelos governos. Oliveira e Araújo (2005) consideram que eles têm potencial de favorecer a garantia ao direito à educação, por meio do acesso, das condições de atendimento e permanência da população escolar. Enguita (1995) os vê como contribuição no atendimento às demandas do mercado e Freire (1987) observa que eles podem levar à conscientização e à transformação social dos sujeitos.

Embora estes autores citados destaquem as diferentes perspectivas $\mathrm{e}$ possibilidades de configuração da qualidade da educação por seu caráter, Gadotti (2009) apresenta o termo, representando um novo paradigma de educação que deverá ser reconstruído,

\begin{abstract}
Qualidade significa melhorar a vida das pessoas, de todas as pessoas. Na educação, a qualidade está ligada diretamente ao bem-viver de todas as nossas comunidades, a partir da comunidade escolar. A qualidade na educação não pode ser boa se a qualidade do professor, do aluno, da comunidade é ruim. Não podemos separar a qualidade da educação da qualidade como um todo, como se fosse possível ser de qualidade ao entrar na escola e piorar a qualidade ao sair dela. Por isso, o tema qualidade é tão complexo. Não basta melhorar um aspecto para melhorar a educação como um todo (GADOTTI, 2009, p.7).
\end{abstract}

Gadotti (2009) ressalta as dimensões social, cultural e política que o termo qualidade envolve, considerando a sua complexidade. Já a visão internacional compreende a qualidade como algo vinculado ao contexto econômico e produtivo. Esta visão está destacada no Relatório Delors (DELORS, 2004), ao se referir ao objetivo educacional a ser alcançado por diversos países. Esse objetivo educacional foi difundido mundialmente no final da década de 1990 e sua base fundamental era a aprendizagem ao longo da vida.

Dessa forma, o centro das atenções da qualidade da educação dos processos educativos, condições de infraestrutura e recursos humanos foi deslocado para os resultados educacionais, com destaque para a aprendizagem. Macedo (2002) relata que 
essa aprendizagem deve valorizar as competências pessoais. Além disso, o Relatório Delors (2004) reforça que essa aprendizagem deve favorecer a:

[...] aprender a conhecer, isto é, adquirir os instrumentos da compreensão; aprender a fazer para poder agir sobre o meio envolvente; aprender a viver juntos, a fim de participar e cooperar com os outros em todas as atividades humanas; finalmente aprender a ser, via essencial que integra as três precedentes (DELORS, 2004, p. 90).

Segundo Miranda (1997), isso leva ao estabelecimento de um novo padrão de conhecimento, no qual a escola não é mais o principal espaço de aprendizagem, uma vez que os conhecimentos, saberes e informações poderão ser acessados e adquiridos através dos novos recursos tecnológicos. A autora considera que os indivíduos deverão aprender a buscar a informação e utilizá-la, já que o novo padrão de conhecimento será: “[...] menos discursivo, mais operativo, menos particularizado, mais interativo, comunicativo; menos intelectivo, mais pragmático; menos setorizado, mais global, não apenas fortemente cognitivo, mas também valorativo" (MIRANDA, 1997, p. 41).

Diante dessa análise, a qualidade da educação deixa de ser um aspecto retratado como uma questão local e passa a ter dimensões globais, de modo a envolver a garantia de direitos e o atendimento das demandas educacionais.

\section{A Qualidade da Educação e a EJA}

A Educação de Jovens e Adultos (EJA) é uma modalidade da educação básica estabelecida pela LDB 9.394/1996 e destinada aos que não tiveram, na idade considerada adequada, acesso ao ensino fundamental e médio, ou não tiveram condições de dar continuidade aos estudos (BRASIL, 1996). Como parte da educação básica e com inúmeras especificidades, a EJA espera por uma educação de qualidade. O termo "qualidade" aparece na Constituição Federal de 1988 no artigo 206, inciso sétimo, afirmando que o ensino será ministrado com a garantia de padrão de qualidade. No artigo 211, parágrafo primeiro, que trata do regime de colaboração entre União, os Estados, o Distrito Federal e os Municípios, fala da existência de um padrão mínimo da qualidade do ensino que possa garantir equalização de oportunidades educacionais mediante assistência técnica e financeira aos Estados, ao Distrito Federal e aos Municípios através da função redistributiva e supletiva. O artigo 214 estabelece a criação de um plano nacional de educação com duração decenal e que tem como objetivo a articulação de um sistema nacional de educação em regime de colaboração, através de diretrizes, metas e 
objetivos definidos (BRASIL, 1988). A Lei de Diretrizes e Bases da Educação Nacional LDB n 9.394/1996 (BRASIL, 1996) endossou o conceito de "qualidade". O Parecer 11/2000 estabeleceu as Diretrizes Curriculares Nacionais para a Educação de Jovens e Adultos (BRASIL, 2000). Encontra-se nele a ideia de garantia do direito a uma escola de qualidade, de padrões mínimos a serem estabelecidos para a qualidade de ensino, para a qualidade de aprendizagem, enfatizando as peculiaridades da EJA.

A Resolução CNE/CB n.3, de 15 de junho de 2012, instituiu Diretrizes Operacionais para a Educação de Jovens e Adultos (BRASIL, 2010c). O Documento aborda a garantia do padrão de qualidade e o padrão mínimo de qualidade, considerando a atenção ao processo educativo em infraestrutura, gestão, formação, valorização dos profissionais da educação, financiamento, jornada escolar, organização pedagógica, entre outros, o direito a uma educação de qualidade, à qualidade social da educação, à exigibilidade da qualidade social, à qualidade de ensino, à qualidade do processo educativo, ao acesso e à permanência do aluno. Todos estes aspectos com ênfase na EJA. Destacam-se alguns pontos que podem impactar a qualidade da EJA: a qualidade estabelecida pelos respectivos sistemas, a qualidade dos professores de EJA, a qualidade dos profissionais da educação, a qualidade da gestão, a qualidade das ações que determinam a qualidade esperada na ação educativa.

Ao observar o sistema educacional brasileiro como um todo, pode-se notar que existem políticas educacionais condizentes com as demandas da EJA: cooperação efetiva entre os entes federados, estabelecimento de diagnósticos, diretrizes e metas que estão atreladas a um compromisso com a efetivação das mesmas, além de indicação de recursos suficientes para a manutenção e aprimoramento da modalidade são indicadores de qualidade. Porém, parte dos docentes da EJA não possui formação específica para atuar na modalidade. Ao desconhecer como colocar em prática seu trabalho, transformam as aulas de EJA em uma reprodução dos conteúdos trabalhados no ensino regular. Contribuem para complicar este cenário a falta de concurso público especifico para se trabalhar junto à modalidade EJA, rotatividade de professores, a inexistência de cursos de formação e aprimoramento profissional.

Portanto, ações para formação dos docentes que atuarão na EJA, condições de trabalho, de estrutura e de suporte de apoio para o funcionamento da EJA, tais como aulas em horários que atendam às necessidades dos alunos, secretaria da escola funcionando para atendimento do aluno da EJA, equipe pedagógica de apoio e específica para EJA, 
escolas que recebam, atendam e prestem um serviço de respeito ao aluno da EJA também são indicadores de qualidade.

\section{A educação de jovens e adultos em Campinas/SP}

O sistema educacional do município de Campinas/SP é composto por três redes de ensino: estadual (Secretaria Estadual de Campinas), municipal (Secretaria Municipal de Campinas) e privada (Secretaria Estadual de Educação). Baseado nessa estrutura e para uma melhor compreensão e análise da qualidade da educação de jovens e adultos no município, foi realizada a delimitação das redes estadual e municipal que apresentavam maior representatividade. Sobre a legislação que regulamenta a rede estadual de ensino e a qualidade da educação de jovens e adultos, o Quadro 1 indica as orientações normativas que a orientam.

Quadro 1: Documentos legais e indicativos de qualidade na EJA da Rede Estadual de São Paulo.

\begin{tabular}{|c|c|c|c|}
\hline Ano & Documento & Dispõe & Qualidade na EJA \\
\hline 2009 & $\begin{array}{l}\text { Deliberação CEE N.o } \\
82 / 2009\end{array}$ & $\begin{array}{l}\text { Estabelece as diretrizes para } \\
\text { os Cursos de Educação de } \\
\text { Jovens e Adultos em nível do } \\
\text { Ensino Fundamental e Médio, } \\
\text { instalados ou autorizados pelo } \\
\text { Poder Público no Sistema de } \\
\text { Ensino do Estado de São Paulo }\end{array}$ & $\begin{array}{l}\text { Art. } 37 \text { - a educação de jovens e } \\
\text { adultos será destinada àqueles que } \\
\text { não tiveram acesso ou continuidade } \\
\text { de estudos no ensino fundamental e } \\
\text { médio na idade própria. } \\
\S 2^{\circ} \text { - O Poder Público viabilizará e } \\
\text { estimulará o acesso e a permanência } \\
\text { do trabalhador na escola, mediante } \\
\text { ações integradas e complementares } \\
\text { entre si”. }\end{array}$ \\
\hline 2010 & $\begin{array}{l}\text { Resolução SE 3, de 13- } \\
\text { 1-2010 }\end{array}$ & $\begin{array}{l}\text { Dispõe sobre alterações na } \\
\text { organização dos cursos de } \\
\text { Educação de Jovens e Adultos, } \\
\text { mantidos pelas escolas } \\
\text { estaduais }\end{array}$ & $\begin{array}{l}\text { Artigo } 1^{\circ} \text { - Os Cursos de Educação } \\
\text { de Jovens e Adultos - EJA, de } \\
\text { frequência obrigatória às aulas } \\
\text { (presenciais) ou de presença flexível } \\
\text { e atendimento individualizado, } \\
\text { implementados pelos Centros } \\
\text { Estaduais de Educação de Jovens e } \\
\text { Adultos - CEEJAs, passarão a adotar, } \\
\text { em caráter obrigatório, a partir de } \\
\text { 2010, materiais didáticos de apoio, } \\
\text { organizados e selecionados por esta } \\
\text { Pasta, consolidados como Propostas } \\
\text { Curriculares dos cursos regulares de } \\
\text { Ciclo II do Ensino Fundamental e do } \\
\text { Ensino Médio do Estado de São } \\
\text { Paulo, para os alunos ingressantes e } \\
\text { em continuidade; }\end{array}$ \\
\hline
\end{tabular}

Fonte: SEE-SP. Disponível em <http://www.educacao.sp.gov.br>. Acesso em 10/10/2012. 
Os atos normativos no quadro 1 referem-se à qualidade da EJA, através da garantia do acesso, da permanência e das condições materiais de apoio aos alunos matriculados. A questão principal está em garantir e proporcionar o cumprimento da oferta e do direito à educação, àqueles que não tiveram oportunidade de acesso ou de continuidade de estudos na idade própria, cumprindo os preceitos normativos presentes na Constituição Federal de 1988 (BRASIL, 1988) e LDB n. 9.394/1996 (BRASIL, 1996).

Em Campinas/SP, a qualidade de ensino é entendida tanto na rede municipal quanto na rede estadual como a garantia do acesso, permanência e oferta de condições materiais, físicas e estruturais que deverão ser destinadas aos alunos matriculados. De acordo com a Secretaria Municipal de Educação (SME) de Campinas, a qualidade de ensino deve ser:

[...] entendida como o melhor que uma comunidade escolar pode conseguir frente às suas reais condições, com o objetivo de servir a população naquilo que é específico da educação: formação e instrução. [...] A qualidade não é optativa no serviço público. É uma obrigação. Deve incluir os processos que conduzem à emancipação humana e ao desenvolvimento de uma sociedade mais justa (SME, 2007, p. 76).

A Secretaria Municipal de Educação de Campinas (SME, 2007) compreende que a qualidade do ensino na rede municipal, incluindo a EJA, deverá contemplar:

\footnotetext{
O estudo, sugestão e deliberação juntamente com a Secretaria Municipal de Educação medidas que visam a expansão qualitativa do Ensino Municipal; A universalização do ensino, garantia dos padrões mínimos de qualidade de ensino, definidos como variedade e quantidade mínimas, por aluno, de insumos indispensáveis ao desenvolvimento do processo de ensino-aprendizagem. A viabilização de projetos e programas especiais para crianças, jovens e adultos em situação de vulnerabilidade social. O Sistema Municipal de Ensino, assegurada sua autonomia, organizará em regime de colaboração junto ao Sistema Estadual de Ensino o atendimento adequado à demanda,

A criação das bases de uma política de recursos humanos capaz de conduzir de forma mais eficaz o desempenho, a qualidade, a produtividade e o comprometimento do integrante do Quadro do Magistério com os resultados do seu trabalho, estabelecimento do piso de vencimento (SME, 2007).
}

Após essa proposta, deu-se uma nova atenção para a presença dos inúmeros problemas que impactam a modalidade EJA e que vinham sendo discutidos por inúmeros autores (BRUNEL, 2004; RIBEIRO, 2001; PAIVA, MACHADO, IRELAND, 2004; HADDAD, 2002): a separação entre a modalidade e a educação regular, a falta de elo entre os programas de alfabetização e pós-alfabetização, a junção de jovens e adultos em um mesmo ambiente, a possibilidade de qualificação para o trabalho, a articulação da 
modalidade com a formação profissional e a necessidade de conclusão da educação básica, entre outros.

Apesar das políticas públicas para a EJA encontrarem respaldo nas diretrizes estabelecidas pelo Governo Federal e pelos Estados e Municípios, à busca da garantia do atendimento, as iniciativas dos Estados e Municípios relativas à modalidade EJA têm sido insuficientes, diante das reais necessidades da população.

\section{Os docentes da EJA do município de Campinas}

Baseado na pesquisa "Diagnóstico da qualidade de ensino na Educação de Jovens e Adultos", financiada pelo Observatório da Educação/CAPES, foi feito um recorte sobre o Município de Campinas no ano de 2013. Neste recorte foram aplicados questionários para 198 docentes da rede estadual e municipal de ensino público da Educação de Jovens e Adultos (JEFFREY et al., 2014). Os docentes que responderam a pesquisa estão divididos nos níveis de Alfabetização de Jovens e Adultos, anos iniciais do Ensino Fundamental (FUMEC), Anos Finais do Ensino Fundamental (EJA) e Ensino Médio (EJA).

Os processos e as relações envolvendo a qualidade na educação de jovens e adultos em Campinas foram observados a partir de questionários aplicados aos docentes. Este quadro foi composto com 7 dimensões:

1. Insumos Financeiros e de Infraestrutura;

2. Gestão Pedagógica;

3. Prática Pedagógica e Processo de Ensino e Aprendizagem

4. Avaliação

5. Formação Continuada

6. Relações no espaço escolar

7. Relações no entrono escolar

O perfil desses docentes é de pouco menos da metade $^{1}$ com idades entre 41 a 50 anos, graduados inicialmente em Letras, Matemática e Pedagogia e a maior parte é do quadro efetivo e do sexo feminino. A maioria dos docentes atua na EJA a menos de 10

\footnotetext{
${ }^{1}$ Serão usados os termos "totalidade" $=($ mais de $90 \%)$, "maioria" $=($ mais de $60 \%)$, "mais/menos da metade" $=(40 \%$ a $60 \%)$, "pequena parte" $=($ menos de $25 \%)$, para facilitar a leitura. Os números exatos podem ser consultados no Relatório da Pesquisa em (JEFFREY et al., 2014)
} 
anos. Cerca da metade tem alguma pós-graduação (especialização, mestrado ou doutorado).

Mais da metade desses docentes responderam não receber formação para ministrar aulas na EJA. Também mais da metade declarou que foi por escolha própria o ato de ministrar aulas na EJA.

Dentro dos docentes entrevistados, mais da metade trabalha em duas ou mais escolas, onde a maioria dessas escolas não oferece a modalidade de ensino EJA.

\section{1 - Insumos Financeiros e de Infraestrutura}

Sobre a infraestrutura da escola, percebe-se que a sala de aula é o ambiente escolar comum a todas as escolas com EJA nas redes estadual e municipal de ensino. A sala de vídeo é o segundo ambiente mais utilizado, seguidos pela sala de informática e sala de leitura. Os ambientes menos utilizados são: laboratórios, quadras poliesportivas e área de recreação.

Pouco menos da metade dos docentes considerou a sala de aula como o espaço mais importante para o desenvolvimento do trabalho com a EJA. Uma pequena parte considera a sala de informática como um espaço de contribuição significativa para a aprendizagem do aluno.

Quanto ao financiamento, a maioria dos docentes conhece as fontes de recebimento dos recursos da escola: FUNDEB, Mais Educação, Verbas do MEC. A maioria acredita que não há recursos específicos destinados para as necessidades da EJA.

Para a maioria, a escola não se articula com outras instituições públicas ou privadas para o financiamento de projetos, formação dos docentes, atividades pedagógicas e esportivas.

\section{2 - Gestão Pedagógica}

As escolas realizam campanhas de divulgação da EJA semestralmente com o objetivo de matricular os interessados. Os métodos utilizados são nessa ordem: a exposição de faixas e cartazes; apresentações orais feitas por meio dos alunos e de diferentes segmentos da escola. 
A maioria dos docentes conhece a legislação que regulamenta a EJA e se orienta pela legislação que a regulamenta na condução do seu trabalho e nos espaços para participação coletiva da escola. As Diretrizes Curriculares da EJA e o Currículo Oficial das redes municipais e estaduais, consolidados em documentos como Proposta PolíticaPedagógica, Planos de Cursos e Normas Regimentais, são a principal forma de orientação.

Para a maioria dos docentes, a escola conta com uma Proposta Pedagógica destinada à EJA e ela contempla as suas diretrizes legais.

Sobre a evasão nas classes de EJA, praticamente a totalidade dos docentes confirma a existência de índices muito altos de evasão. As causas desse abandono são (por ordem de importância) 1- Trabalho; 2- Problemas familiares; 3- Mudança de bairro; 4- Distância a ser vencida para chegar da residência/trabalho até a escola; 5- Desinteresse; 6- Medo do entorno.

A escola apura e monitora a frequência dos alunos matriculados na EJA, especialmente alunos menores de 18 anos. A escola realiza um processo de identificação das causas e dos motivos das faltas dos alunos da EJA. Na intenção de reduzir a evasão, a escola atua com as estratégias (por ordem): 1- Planejamento coletivo; 2- Inclusão de aulas diversificadas e atraentes no cotidiano escolar; 3- oferecimento aos alunos de formas diversas de cultura, lazer e entretenimento; 4- realização de pesquisas a fim de reconhecer motivos que levam o aluno a evadir; 5- realização de parcerias com o entorno escolar.

\section{3 - Prática Pedagógica e Processo de Ensino e Aprendizagem}

A totalidade dos docentes afirmou que planeja as atividades para os alunos da EJA e realiza o levantamento junto aos alunos para identificar o que eles conhecem. A maioria faz o planejamento de forma individual e o restante faz coletivamente com outros professores.

Sobre os recursos didáticos utilizados nas aulas, a ordem de importância: 1-o caderno e quadro negro, 2-livro didático, 3-filmes, 4-jornal, 5-revista, 6-internet, 7-livros de literatura, 8-obras de arte. 
As atividades realizadas com seus alunos são: palestras, cinema, peças de teatro, visita a bibliotecas, museus, espaços da comunidade, eventos musicais. A frequência dessas ações foi caracterizada pela totalidade como: às vezes.

A maior parte respondeu que existem atividades de recuperação paralela para alunos com dificuldades de aprendizagem na EJA. As deficiências dos alunos da EJA incluem (por ordem): deficiência intelectual, motora, auditiva e visual. O atendimento é fornecido através de salas de recursos (educação especial) por docentes especialistas.

Os recursos/materiais pedagógicos disponíveis para a EJA foram apontados pela seguinte ordem de prioridade: 1-livros didáticos, 2-televisão, 3-material escolar (caderno, lápis, borracha...), 4-vídeo cassete/DVD, 5-Sala de informática, 6-acervo de biblioteca, 7-aparelho de som, 8-datashow, 9-materiais de papelaria diversos, 10-livros paradidáticos, 11-acervo de CDs e DVDs da escola.

\section{4 - Avaliação}

Os instrumentos de avaliação mais utilizados são (por ordem): 1-provas e testes formulados pelo docente, 2- participação do aluno em aula, 3-trabalhos em grupo e 4trabalhos de pesquisa individuais.

O julgamento que o docente faz em relação ao desempenho dos alunos após o desenvolvimento do seu trabalho pedagógico é entendido pela maioria como parcialmente correspondido. Um dos fatores que podem justificar esse resultado parcial talvez seja que o processo de avaliação é compartilhado e decidido com os alunos somente para uma pequena parte dos docentes que responderam a pesquisa, definindo critérios objetivos e transparentes de avaliação. Uma pequena parte dos docentes respondeu que conta com a participação dos alunos da EJA nos Conselhos de Classe/séries, reforçando, mais uma vez, a falta de critérios e participação dos alunos na avaliação de desempenho realizado pelos docentes nas escolas.

Os alunos que apresentam baixo desempenho nas avaliações são acompanhados pela maioria dos docentes. Pouco menos da metade dos docentes considera as aulas de reforço/recuperação a forma mais comum de acompanhar e recuperar os conteúdos não aprendidos pelos alunos. 
Não há nenhuma forma específica de avaliação externa para EJA na maioria das escolas, principalmente as da rede estadual. Os indicadores externos como IDESP (indicador estadual das escolas públicas estaduais) e IDEB (indicador federal das escolas públicas e privadas) não incluem a EJA nas suas estatísticas quantitativas e qualitativas.

A maioria dos docentes recebe materiais em apoio à prática pedagógica, mas bem menos da metade dos docentes conseguiu avaliar o material antecipadamente. O material é avaliado como bom pela maioria dos docentes.

\section{5 - Formação Continuada}

Cerca de metade dos docentes de EJA respondeu que existe formação continuada nas redes e que as secretarias de educação são os órgãos responsáveis pelas mesmas. A quase totalidade dos docentes respondeu receber algum incentivo da rede pública a que pertencem para seu desenvolvimento cultural.

\section{6 - Relações no espaço escolar}

Metade dos docentes respondeu que a identificação profissional com a área da EJA é o principal motivo que os mantém trabalhando na modalidade. Os motivos que mais atraem os docentes a trabalhar com a EJA são (por ordem): 1-identificação com alunos jovens e adultos, 2-os saberes já construídos por esses alunos, 3-desenvolver práticas pedagógicas diferenciadas.

A quase totalidade dos docentes da EJA tem um bom relacionamento com a equipe gestora. A maioria desses docentes consegue expor e discutir com os gestores as dificuldades. A maior parte dos docentes da EJA participa do Conselho/Colegiado escolar das escolas.

Os conselhos/colegiados têm a sua disposição informações sobre a EJA em quantidade e qualidade, para que possam realizar proposições para essa modalidade.

A maior parte dos docentes respondeu que suas escolas não possuem organização estudantil. Das escolas que possuem alguma organização estudantil, uma pequena parte possui alunos da EJA que participam da organização. 
A participação dos responsáveis pelos alunos menores da EJA é muito baixa. Ainda assim, a equipe gestora promove o encaminhamento dos alunos da EJA para serviços de saúde, Conselho Tutelar ou outros serviços públicos.

A grande maioria dos docentes considera que a escola acolhe os alunos da EJA. A maioria também afirma que a escola desenvolve atividades educativas que favorecem a resolução de conflitos e o enfrentamento de questões de discriminação. A atividade principal desenvolvida é a realização de projetos que incluam palestras.

\section{7 - Relações no entorno escolar}

A escola recebe alunos sempre que procurada, independente da época do ano e do período. Pouco mais da metade dos docentes considera que ainda existe contato entre escola e ex-alunos. As principais formas de contato com o entorno são: o oferecimento de atividades educativas para a comunidade local através de oficinas, palestras, cursos de língua estrangeira e atividade esportiva; as parcerias com ONG e com outras instituições. Mas, a totalidade dos educadores considera que não existe parceria com alguma instituição ligada à promoção da leitura e da escrita.

A comunidade do entorno escolar tem acesso às instalações da escola (por ordem): 1-quadra esportiva, 2-biblioteca, 3-sala de informática.

Metade dos docentes respondeu não desenvolver atividades que colaboram para minimizar problemas identificados no entorno escolar.

\section{Considerações finais}

A pesquisa documental permitiu constatar a presença do termo qualidade do ensino na educação de jovens e adultos (EJA), a partir da análise da legislação e dos documentos oficiais produzidos pelas Secretarias Estadual e Municipal de ensino. A questão da qualidade do ensino na EJA foi apresentada por meio de três dimensões: normativa, política e educativa.

Ao se abordar a modalidade EJA surgem inúmeras necessidades. Ao mesmo tempo, propõe-se uma segunda chance e uma nova oportunidade. Percebe-se no público da EJA a percepção de imagem de uma escola que tem seu valor e sua qualidade percebida como necessária e importante na vida das pessoas. 
A questão principal da qualidade na educação está em sua complexidade de medir. Na educação não basta só avaliar. É necessário implementar ações que deem conta de problemas como falta de financiamento adequado, de profissionais preparados, de planejamento das ações, de programas curriculares voltados para as características dos alunos e com ênfase na aprendizagem, no respeito e na superação.

Torna-se necessário que cada sistema, ao estabelecer o seu compromisso com a EJA, garanta regimentos que a contemplem, projetos políticos pedagógicos específicos para a modalidade e construídos coletivamente, elaboração de plano de ação e de gestão da escola para com a modalidade EJA. Apesar de todo o suporte teórico da qualidade na Legislação Federal, as ações a serem executadas precisam ser construídas junto àqueles que buscam a volta à escola e daqueles que se estão na escola para executar esse trabalho educativo.

A qualidade de ensino na EJA no município de Campinas, tanto na rede estadual quanto municipal de ensino, é entendida como um processo, com vistas a garantir o direito à educação por meio de condições de acesso, permanência e oferta de funcionamento das unidades escolares e atendimento à população, alinhada às diretrizes da Constituição Federal (BRASIL, 1988) e da Lei de Diretrizes e Bases da Educação LDB nº 9.394/1996 (BRASIL, 1996).

Sobre Campinas/SP, foi possível observar que a sua rede municipal tem uma concepção abrangente sobre a qualidade de ensino na modalidade EJA, com ênfase na estrutura, funcionamento, organização, oferta de condições e investimento no quadro docente, o que indica, pelo menos nos documentos normativos, o comprometimento com a qualidade de ensino.

Sobre as 7 dimensões de indicadores de qualidade apontadas na pesquisa sobre o Município de Campinas/SP (Insumos Financeiros e de Infraestrutura; Gestão Pedagógica; Prática Pedagógica e Processo de Ensino e Aprendizagem; Avaliação; Formação Continuada; Relações no espaço escolar; Relações no entrono escolar), alguns itens chamaram a atenção.

Têm-se uma percepção geral dos docentes de que a sala de aula é o ambiente escolar mais utilizado com a EJA nas redes estadual e municipal de ensino. Apenas a seguir estão a sala de vídeo e a sala de informática. 
A maioria dos docentes orienta-se pela legislação que regulamenta a EJA e pelas diretrizes curriculares e currículo oficial das redes estadual e municipal. A percepção geral desses docentes é que a escola conta com uma Proposta Pedagógica destinada à EJA e que ela contempla as suas diretrizes legais.

Confirma-se a questão do alto índice de evasão nas salas de EJA, apresentando o trabalho do aluno e problemas familiares como as primeiras razões dessa evasão. Desinteresse e medo de retornar estão nas últimas opções. A percepção dos educadores é de uma evasão ligada mais a dificuldades da vida adulta (trabalho, relações) do que a problemas de ordem pessoal e interna, como desinteresse ou medo.

Os educadores afirmam que planejam as atividades da EJA e fazem o levantamento do que os alunos já dominam de conhecimento, buscando aulas mais ajustadas à realidade dos alunos e demonstrando uma preocupação com as especificidades da EJA. Mas a maioria utiliza o planejamento individual, não chegando a construir uma proposta coletiva com os demais educadores.

Em sintonia de considerar a sala de aula como o principal espaço de aprendizagem, os recursos didáticos mais utilizados são o caderno, o quadro negro e o livro didático.

A avaliação predominante é a de provas e testes formulados pelo educador e a participação dos alunos durante as aulas. Os educadores acompanham os alunos que têm baixo desempenho nessas avaliações. A forma considerada mais comum de acompanhar e recuperar os conteúdos é a aula de reforço.

Os educadores recebem algum tipo de incentivo da rede pública para o seu desenvolvimento cultural e percebem a existência de formação continuada nas redes de ensino suprida pelas Secretarias de Educação.

Destaca-se, ainda, que a metade dos educadores se identifica com a EJA e este é o motivo de continuarem trabalhando na Modalidade, por se identificarem com os alunos jovens e adultos, seus saberes já construídos e pela possibilidade de desenvolver práticas pedagógicas diferenciadas.

Nas relações com o ambiente externo, a escola recebe os alunos de EJA em qualquer época do ano. É mantido também algum contato com os alunos egressos da EJA. A forma da escola de se relacionar com a comunidade à sua volta é principalmente através 
de oficinas, palestras e cursos de língua estrangeira. Porém, na percepção dos educadores, carecem de parcerias com instituições ligadas à promoção da leitura.

Embora os atos e documentos normativos indiquem o comprometimento com a qualidade de ensino, percebe-se que ainda é um processo desafiador tanto para a Secretaria Estadual de Educação quanto para a Secretaria Municipal de Campinas. Os Governos têm escolhido priorizar a educação básica regular, contemplando os níveis obrigatórios de ensino. Apesar dos avanços e das percepções captadas na pesquisa sobre Campinas/SP, a EJA ainda precisa de mais indicadores de qualidade, que contemplem as diversidades de experiências e vivências dos alunos e dos profissionais envolvidos nesse processo.

\section{REFERÊNCIAS BIBLIOGRÁFICAS}

BRANDÃO, C. R. O que é educação? São Paulo: Brasiliense, 1992.

BRASIL. Censo Escolar 2011. 2011. Disponível em: <http://portal.inep.gov.br/basicacenso-escolar-matricula>. Acesso em: 23/07/2012.

Resolução n. ${ }^{\circ}$ 4, de 13 de Julho de 2010. Define Diretrizes Curriculares Nacionais Gerais para a Educação Básica. 2010a. Disponível em: <http://portal.mec. gov.br/index.php?Itemid=866\&id=15074\&option=com_content\&view=article $>$. Acesso: em 08/03/2012.

Resolução CNE/CEB n. ${ }^{\circ}$ 3, de 15 de junho de 2010. Institui Diretrizes Operacionais para a Educação de Jovens e Adultos nos aspectos relativos à duração dos cursos e idade mínima para ingresso nos cursos de EJA; idade mínima e certificação nos exames de EJA; e Educação de Jovens e Adultos desenvolvida por meio da Educação a Distância. 2010b. Disponível em: <http://portal.mec.gov.br/index.php?option=com content\&view=article\&id=12992: diretrizes-para-a-educacao-basica\&catid=323:orgaosvinculados >. Acesso em: 08/03/2012.

Educação de Jovens e adultos: Ensino Fundamental Integrado ao Ensino Profissionalizante, 2010c.

. Parecer 11/2000 - Diretrizes Curriculares Nacionais para a Educação de Jovens e Adultos. 2000. Disponível em: <http://portal.mec.gov.br/cne/arquivos/ pdf/PCB11_2000.pdf>. Acesso em: 08/03/2012.

Lei n. ${ }^{\circ}$ 9.394, de 20 de dezembro de 1996. Estabelece as diretrizes e bases da Educação Nacional. 1996. Disponível em: <http://www.planalto.gov.br/ ccivil_03/leis/L9394.htm>. Acesso em: 08/03/2012. 
Constituição da República Federativa do Brasil. 1988. Disponível em: <http://www.planalto.gov.br/ccivil_03/Constituicao/Constitui\%C3\%A7ao.htm>. Acesso em: 08/03/2012.

BRUNEL, C. Jovens cada vez mais jovens na educação de jovens e adultos. Porto Alegre: Mediação, 2004.

SME. SECRETARIA MUNICIPAL DE EDUCAÇÃO DE CAMPINAS. Avaliação Institucional Participativa (Relatório), 2007.

DELORS, J. et al. Educação: um tesouro a construir. Relatório para a UNESCO da Comissão Internacional sobre Educação para o século XXI. 9 ed. São Paulo: Cortez/ UNESCO/MEC, 2004.

DEMO, P. Avaliação Qualitativa. 7 ed. rev. Campinas, SP: Autores Associados, 2002. FONSECA, M. Políticas públicas para a qualidade da educação brasileira: entre o utilitarismo econômico e a responsabilidade social. Cadernos CEDES, vol.29, n.78, p.153-177, ago. 2009.

FREIRE, P. Pedagogia do Oprimido. Rio de Janeiro: Paz e Terra, 1987.

ENGUITA, M. F. O Discurso da qualidade e a qualidade do discurso. In: GENTILI, P.; SILVA, T. T. da. Neoliberalismo, Qualidade Total e Educação: Visões Críticas. 2a . Ed, 1995.

GADOTTI, M. Qualidade na educação: uma nova abordagem. São Paulo: Editora e Livraria Instituto Paulo Freire, 2009.

HADDAD, S. (coord.). Educação de Jovens e Adultos no Brasil (1986-1998). Brasília: MEC/INEP/ Comped, 2002.

JEFFREY, D. C. et al. Diagnóstico da qualidade de ensino na Educação de Jovens e Adultos - O caso de Campinas, SP. Relatório de Pesquisa. 2014.

MACEDO, L. de. Sobre a ideia de competência. In: PERRENOUND, P. et al. As competências para ensinar no século XXI: A formação dos professores e o desafio da avaliação. Porto Alegre: Artmed, 2002, p.137-155.

MIRANDA, M. G. Novo Paradigma de Conhecimento e Políticas Educacionais na América Latina. Cadernos de Pesquisa, n. 100, p.37-48, mai 1997.

OLIVEIRA, R. P. de; ARAÚJO, G. C. de. Qualidade do ensino: uma dimensão da luta pelo direito à educação. Revista Brasileira de Educação, n. 28, p. 5-23, jan./fev./ mar./ abr. 2005.

PAIVA, J.; MACHADO, M. M.; IRELAND, T. (Orgs.) Educação de Jovens e Adultos: uma memória contemporânea. Brasília: MEC, 2004. 
RIBEIRO, V. M. (org.). Educação de jovens e adultos: novos leitores, novas leituras. Campinas: Mercado de Letras/ALB, 2001.

SÃO PAULO. SECRETARIA ESTADUAL DE EDUCAÇÃO. Resolução SE 3, de 13-1-2010. Dispõe sobre alterações na organização dos cursos de Educação de Jovens e Adultos, mantidos pelas escolas estaduais. 2010. Disponível em:

<http://www.educacao.sp.gov.br>. Acesso em: 02/12/2012.

SÃO PAULO. SECRETARIA ESTADUAL DE EDUCAÇÃO. Deliberação CEE n. ${ }^{\circ}$ 82/2009. Estabelece as diretrizes para os Cursos de Educação de Jovens e Adultos em nível do Ensino Fundamental e Médio, instalados ou autorizados pelo Poder Público no Sistema de Ensino do Estado de São Paulo. 2009. Disponível em:

<http://www.educacao.sp.gov.br>. Acesso em: 02/12/2012.

Recebido em: 30/03/2016

Aprovado em: 10/05/2016 